\title{
Medical Image of the Week: Ascaris Lumbricoides
}

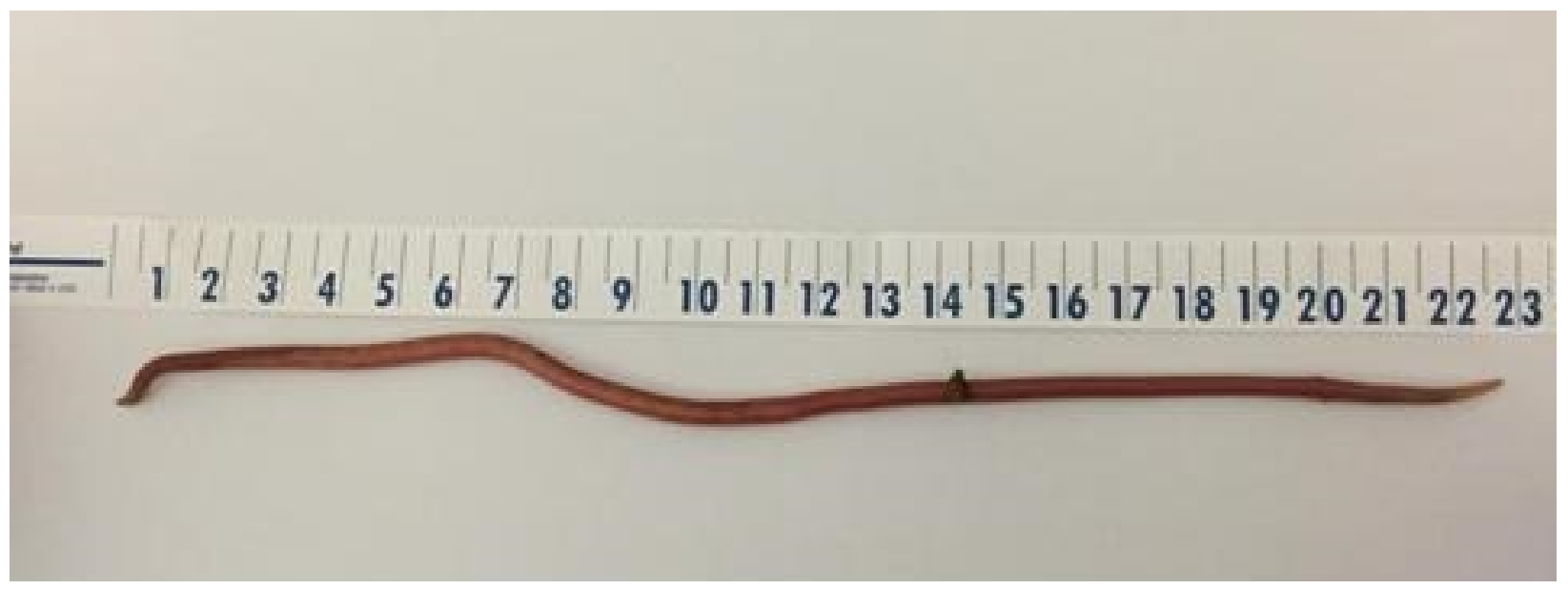

Figure $1.23 \mathrm{~cm}$ adult Ascaris lumbricodes recovered from patient's feces.

A 25 year-old man was admitted to the ICU with acute renal failure and acute respiratory failure from fluid overload after attempting to cross the border. The patient was successfully extubated after five days of mechanical ventilation and renal replacement therapy. Following extubation, the patient had a bowel movement and passed a $23 \mathrm{~cm}$ adult Ascaris lumbricoides. He was treated with a single dose of albendazole $400 \mathrm{mg}$.

Ascariasis is a very common helminthic infection, particularly in pediatric populations, and affects mostly the gastrointestinal tract. When infective eggs are swallowed by the host, larvae hatch in the GI tract. The larvae invade the GI mucosa and then are brought into the lungs via portal circulation. The larvae can then move up the tracheobronchial tree and then are swallowed into the GI tract where the mature worms form (1).

While our patient had a simple gastrointestinal infection, several pulmonary complications of ascariasis have been reported (2). Adult worms can cause largyngospasm as well as mechanical obstruction of the airway which can result in cardiac arrest $(3,4)$. This migration of worms from the stomach to the trachea may be related to the use of anesthetics and the subsequent relaxation of the lower esophageal sphincter. Ascaris larvae have been implicated in Loeffler's syndrome, also described as simple pulmonary eosinophilia, characterized by transient pulmonary infiltrates and eosinophilia with a usually benign course.

Candy Wong ${ }^{1}$; Aaron Fernandes ${ }^{2}$, Jennifer Huang ${ }^{2}$, and Sachin Chaudhary ${ }^{1}$

${ }^{1}$ Division of Pulmonary, Critical Care, Allergy, and Sleep Medicine.

${ }^{2}$ Department of Medicine

University of Arizona

Tucson, AZ 


\section{References}

1. Centers for Disease Control and Prevention. Parasites - Ascariasis. Biology. Available at: http://www.cdc.gov/parasites/ascariasis/biology.html (accessed 1/13/2015).

2. Li QY, Zhao DH, Qu HY, Zhou CN. Life-threatening complications of ascariasis in trauma patients: a review of the literature. World J Emerg Med. 2014;5(3):165-70. [CrossRef] [PubMed]

3. Maletin M, Veselinović I, Stojiljkovic GB, Vapa D, Budakov B. Death due to an unrecognized ascariasis infestation: two medicolegal autopsy cases. Am J Forensic Med Pathol. 2009;30(3):292-4. [CrossRef] [PubMed]

4. Husain SJ, Zubairi AB, Sultan N, Beg MA, Mehraj V. Recurrent episodes of upper airway blockage associated with Ascaris lumbricoides causing cardiopulmonary arrest in a young patient. BMJ Case Rep. 2009;2009. pii: bcr01.2009.1415. [CrossRef] [PubMed] 